\title{
A PRODUÇÃO DE MATERIAL DIDÁTICO PARA O ENSINO SUPERIOR BASEADA NA METODOLOGIA DE SALA DE AULA INVERTIDA
}

Rafael Dias Rios de Souza ${ }^{1}$ Sandra Maria Fonseca da Costa ${ }^{2}$

Resumo - Este estudo tem como objetivo discutir uma proposta nova de metodologia de ensinoaprendizagem, que será utilizada no ambiente de uma instituição de ensino. Essa proposta tem como base o uso de ferramentas tecnológicas e inovadoras, tais como o procedimento pedagógico denominado Flipped classroom, ou sala de aula invertida. Neste trabalho, apresentamos uma aplicabilidade da metodologia em uma na disciplina Universidade do Vale do Paraíba (UNIVAP), com a finalidade de coletar e processar dados para entender como novas tecnologias vem influenciando o meio educacional.

Palavras-chave: Ciências humanas; Tecnologia; Sala de aula invertida; Inovação pedagógica; Flipped classroom.

${ }_{1}^{1}$ FEA - Faculdade de Educação e Artes/Universidade do Vale do Paraíba, Brasil. E-mail: rafaelrios14@gmail.com. 2 FEA - Faculdade de Educação e Artes/Universidade do Vale do Paraíba, Brasil. E-mail: sandra@univap.br. 